Academic Platform Journal of Engineering and Science

\title{
Farklı Yüksekliğe Sahip Boşluklu Perde Duvarlara ait Davranış Eğrilerinin SAP2000 OAPI ile Elde Edilmesi
}

\author{
*1'Bilal Tayfur, ${ }^{2}$ Ömer Can \\ ${ }^{1}$ Bayburt Üniversitesi Mühendislik Fakültesi İnşaat Mühendisliği Bölümü, Bayburt, bilaltayfur@bayburt.edu.tr, \\ ${ }^{1}$ Bayburt Üniversitesi Mühendislik Fakültesi İnşaat Mühendisliği Bölümü, Bayburt, ocan@ bayburt.edu.tr, \\ Araștırma Makalesi \\ Geliș Tarihi: 06.02.2018 \\ Kabul Tarihi: 02.07.2018
}

\section{Öz}

$\mathrm{Bu}$ çalışma kapsamında, perde duvarlarda açılan veya bırakılan pencere boşluklarının çerçeve davranışı üzerindeki etkileri incelenmiştir. $\mathrm{Bu}$ bağlamda, perde/çerçeve yüksekliği oranı sabit tutularak 5 farklı serbest kolon boyunun elde edilmesini sağlayacak 5 model belirlenmiştir. 5 farklı perde duvar yüksekliğine sahip çerçeveler SAP2000 OAPI aracılığıyla C\# yazılım dili kullanılarak modellenmiştir. Açıkta kalan ve kısa kolon oluşumuna sebep olan boşluklara $1 \mathrm{~cm}$ artırımlarla kanat duvarlar eklenerek analizler yapılmıştır. Analizler çerçevenin kanat duvarsız halinden tam dolu duvar haline kadar devam ettirilmiştir. Bu sayede çerçevelere ait kanat duvar boyuna bağlı davranış değişim grafikleri elde edilmiştir. Modelleme esnasında perde duvar malzemesi, kanat duvar artırımları arasındaki kuvvet aktarımının doğru şekilde gerçekleşebilmesi için $1 \mathrm{~cm} 2$ meshlere ayrılmıştır. Çerçevelere ait ötelenme değerleri ve kısa kolon oluşumu beklenen kesitlerdeki iç kuvvetlerin değişimi yüksek hassasiyetle kayıt altına alınmıştır. Bu bağlamda toplam 750 farklı analiz gerçekleştirilmiştir. Bu analizler neticesinde serbest kolon boyunun kısalmasına bağlı olarak, yanal ötelenme kapasitesinin de doğrusal olmayan biçimde azaldığını ve kısa kolon oluşumu ihtimalinin arttığ 1 görülmüştür.

Anahtar kelimeler: perde duvar, boşluklu perde duvar, sap2000 oapi

\section{Obtaining Behaviour Curves of Shear Walls with Opening with Different Height via SAP2000 OAPI}

${ }^{* 1}$ Bilal Tayfur, ${ }^{2}$ Ömer Can

${ }^{1}$ Bayburt University Faculty of Engineering Department of Civil Engineering, 69100 Bayburt, bilaltayfur@bayburt.edu.tr

${ }^{2}$ Bayburt University Faculty of Engineering Department of Civil Engineering, 69100 Bayburt, ocan@ bayburt.edu.tr

\begin{abstract}
In this study, the effects of openings left on shear walls on frame behaviour were investigated. In this context, 5 models were determined to achieve 5 different free column lengths by keeping the frame/shear wall height ratio constant. Frames with 5 different shear wall heights are modelled using C\# software language via SAP2000 OAPI. Analyses were made by adding wing walls with $1 \mathrm{~cm}$ increments to the openings which causing short column formation. The analyses were continued from the frame without wing wall to the filled frame. Thus behavioural change graphs based on the wing wall length of the frames were obtained. During the modelling, $1 \mathrm{~cm} 2$ mesh size has been selected for the force transfer between the wing wall and shear wall can be achieved correctly. Change of the displacement values and the internal forces in the sections where short column formation is expected are recorded with high precision. A total of 750 different analyses were performed in this context. As a result of these analyses, it was seen that the lateral displacement capacity decreased nonlinearly and the probability of short column formation increased due to the shortening of the free column length.
\end{abstract}

Keywords: shear wall, shear walls with opening, sap2000 oapi

\footnotetext{
*1Sorumlu Yazar: Bayburt Üniversitesi İnşaat Mühendisliği Bölümü/Bayburt, e-Posta: bilaltayfur@bayburt.edu.tr, Tel: +904582111153 (1669)
} 


\section{GÍRİ̧̧}

Dünyada ve ülkemizde geride bıraktığımız yıllar itibariyle önemli sayıda deprem yaşanmıştır. Bu depremlerde çok sayıda insan hayatını yitirmiş, çok daha fazlası da yakınlarını kaybetmiştir. $\mathrm{Bu}$ bağlamda 2007 yılında yayımlanan "Deprem Bölgelerinde Yapılacak Binalar Hakkında Yönetmelik", uzun kenarının kısa kenarına oranı en az 7 olan düşey taşıyıcı elemanları "Perde Duvar" olarak tanımlamaktadır [1]. Bu yönetmeliğe göre; başta bir takım ölçütleri sağlayan yüksek katlı binalar olmak üzere birçok binada perde duvar kullanımı zorunludur. Zira perde duvarların yapıdaki en önemli görevi, sağladığı yüksek rijitlik sayesinde deprem ve rüzgâr yükleri altında yapısal ötelenmeleri çok büyük oranda azaltmaktır. Bu özelliği itibariyle perde duvarlar bir takım çalışmalarda "Deprem Perdesi" adıyla da anılmaktadır [2].

Perde duvarlar bir deprem elemanı olmaları itibariyle, yapının depreme maruz kaldığı süre zarfında yap1 güvenliğini sağlayabilecek seviyede güvenilir tasarlanmalıdır. Bu noktada göz önüne alınması gereken en temel husus, perde duvarların deprem anında hangi iç kuvvetlere maruz kaldığıdır. Bu iç kuvvetler moment, kesme kuvveti ve düşey yükler olarak sıralanabilir. Perde duvar tasarımının deprem etkisi altındaki davranışının bir neticesi olarak en istenmeyen durum, eğilmeden önce kesme kırılmalarının oluşmaya başlamasıdır. Perde duvarlarda oluşacak kesme kırılmaları kendilerini eğik asal çekme çatlağı olarak gösterir. Bu kırılma tipinin gevrek oluşu ve az miktarda enerji tüketmesi de yapının tümünde taşıma kapasitesinin hızlı bir biçimde azalmasına ve nihai olarak yapının göçmesine sebep olur [3].

Perde duvarlar bir yapı elemanı olması itibariyle çoğunlukla çerçeve sistem içerisinde kolonlarla önemli bir etkileşim içerisindedir. Her ikisi de geometri ve davranış biçimi ile bir diğerini etkilemektedir. $\mathrm{Bu}$ durumun en bilinen biçimlenmelerinden birisi de, kolon yüksekliği boyunca devam etmeyen perde duvarın sebep olduğu kısa kolon oluşumu olarak gösterilmektedir. Çerçeve içerisinde yer alan perde duvar, kolonu yanal düzlemde her iki taraftan da eğilme yapamaz hale getirmekte ve kolonun açıkta kalan kısmını kesme kırılması yapmaya zorlamaktadır [4].

Kolon yüksekliğince devam etmeyen perde duvarların kısa kolon oluşumuna sebep olmasına benzer bir şekilde perde duvarlar üzerinde açılan pencere boşlukları da aynı yapısal davranış ile kısa kolon oluşumuna neden olmaktadır. Serbest boyu kisitlanan bu kolonlar, perde duvardaki pencere açıklığı sebebiyle zayıflayan kesitlerin de kesme kırılması yapmasına sebep olarak göçebilmektedir [5].

Yanal yüklemeler altında perde duvarlarda oluşan gerilmelerinin davranışı ve dağılımıyla kısa kolon oluşumu arasında önemli bir ilişki söz konusudur. Perdenin, çerçeveden gelen kuvvetleri birbirine çapraz köşeler arasında aktardığı varsayılmaktadır [6]. Şekil 1'de verilen sanal eşdeğer basınç çubuğu olarak adlandırılan bu kuvvet aktarım hattının kalınlığı Denklem 1, 2 ve 3 'de verildiği gibi bulunmaktadır [7]. Bu denklemlerden de görülebileceği üzere, elastik sınırlar dâhilinde perde duvarlardaki basınç dağılım davranışı kuvvetten bağımsızdır.

\begin{tabular}{rl|}
$w$ & $=0.175\left(\lambda h_{\text {net }}\right)^{-0.4} d$ \\
$\lambda$ & $=\sqrt[4]{\frac{E_{m} t \sin 2 \theta}{4 E_{s} I_{c} h_{\text {net }}}}$
\end{tabular}

İlgili denklemlerde;

$\mathrm{w}=$ Eşdeğer sanal basınç çubuğu genişliğini,

$\lambda=$ Rijitlik azaltma katsayısını,

$\mathrm{h}_{\text {net }}=$ Duvar yüksekliğini,

$\mathrm{d}=$ Eşdeğer sanal basinç çubuğu boyunu,

$\mathrm{E}_{\mathrm{m}}=$ Duvar malzemesinin elastisite modülünü,

$\mathrm{h}=$ Duvar kalınlığını,

$\theta=$ Eşdeğer sanal basınç çubuğunun yatayla yaptığı açıyı,

$\mathrm{E}_{\mathrm{s}}=$ Çerçeve malzemesinin elastisite modülünü,

$\mathrm{I}_{\mathrm{c}}=$ Çerçeve kolonlarına ait atalet momentini,

$\mathrm{L}_{\mathrm{net}}=$ Duvar genişliğini ifade etmektedir.

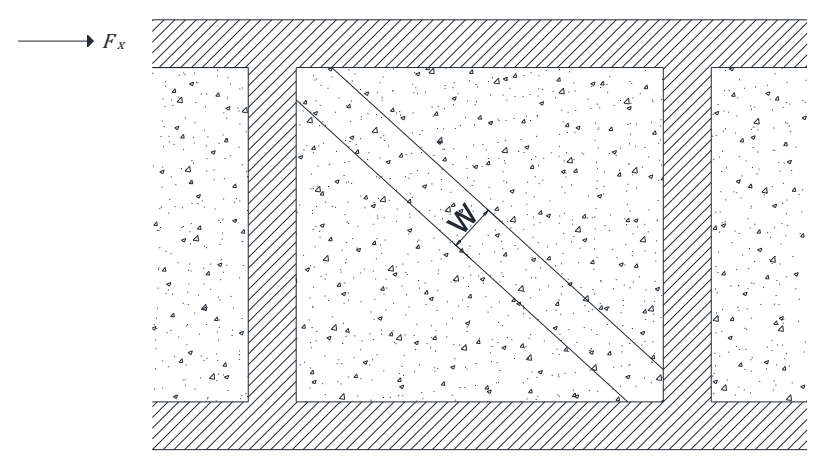

Şekil 1. Sanal eşdeğer basınç çubuğu modeli

Eşdeğer sanal basınç çubuğu yöntemi dolgu duvarlarda hala sıkça kullanılmaya devam etmektedir. Bu çalışmada ise yalnızca ilgili formüller çerçeve özelliklerini belirlemek için kullanılmıştır. Bununla birlikte yapılan deneysel ve analitik çalışmalar göstermektedir ki, boşluklu duvarlarda gerilmelerin aktarılması farklı şekillerde de gerçekleşebilmektedir [8].

Perde duvarlar ve boşluklu perde duvarlar üzerine yapılan çalışmalar ağırlıklı olarak yanal yükleme etkilerini araştırmaktadır. Geçen yıllar içerisinde farklı modelleme ve hesap yöntemleri bu bağlamda literatüre kazandırılmıştır [9]-[16]. Perde duvarlarda bırakılan boşluklar perde duvar davranışlarını yadsınamayacak ölçüde etkilemektedir. Bu tip boşluklar, perde duvarın rijitliğini azaltmakta ve beklenmeyen göçmelere zemin hazırlamaktadır [17]-[25]. Perde duvarlardaki boşluklardan kaynaklanan göçmelerin ani şekilde gerçekleşmesinin temel sebebi genellikle ortaya 
çıkan kısa kolon davranışından kaynaklanmaktadır [26][30].

Matematiksel olarak sonlu elemanlar metodu üzerine inşa edilmiş olan SAP2000 yazılımı günümüzde yapısal analiz alanında etkin biçimde kullanılmaktadır. Yazılımı geliştiren "Computers and Structures" firması, kullanıcı tarafindan daha uyarlanabilir şekilde çalışmasını sağlamak amacıyla SAP2000 yazılımı için bir API (Application Progragramming Interface 'Uygulama Programlama Arayüzü') çıkışı da sağlamıştır. Firmanın OAPI adını verdiği bu çıkış sayesinde modellemeden analize kadar tüm aşamalar başka bir yazılım tarafından yürütülebilmekte ve bu sayede amaca yönelik bir takım analiz sonuçları alınabilmektedir. SAP2000 OAPI çıkışı kullanılarak kodlanacak programlar; VBA, Basic, C\#, Fortran, C++ ve Python yazılım dilleri ile programlanabilmekle birlikte
MATLAB gibi hesaplama temelli dördüncü nesil programlama dilleri ile de yazilabilmektedir [31], [32]. SAP2000 yazılımını geliştiren Computers and Structures firması, OAPI için tanımlanmış tüm fonksiyonları ayrı bir dokuman olarak kullanıcıların erişimine sunmuştur [33].

\section{MATERYAL VE YÖNTEM}

Bu çalışmadaki temel amaç, perde duvarlarda bırakılan bant tipi boşluklardaki boyut değişiminin çerçeve yüksekliğine bağlı olarak çerçeve davranışına olan etkilerini incelemek ve gerekli hallerde bırakılacak boşlukların sebep olduğu dayanım kayıplarını doğru biçimde öngörebilmektir. Yapılardaki bu tip boşlukların sebep olduğu en tehlikeli göçme tipi kısa kolon etkisi kaynaklı kesme göçmesi olarak görünmektedir. Bu sebeple, yapılan analizlerden elde edilen veriler bu bağlamda değerlendirilecektir.

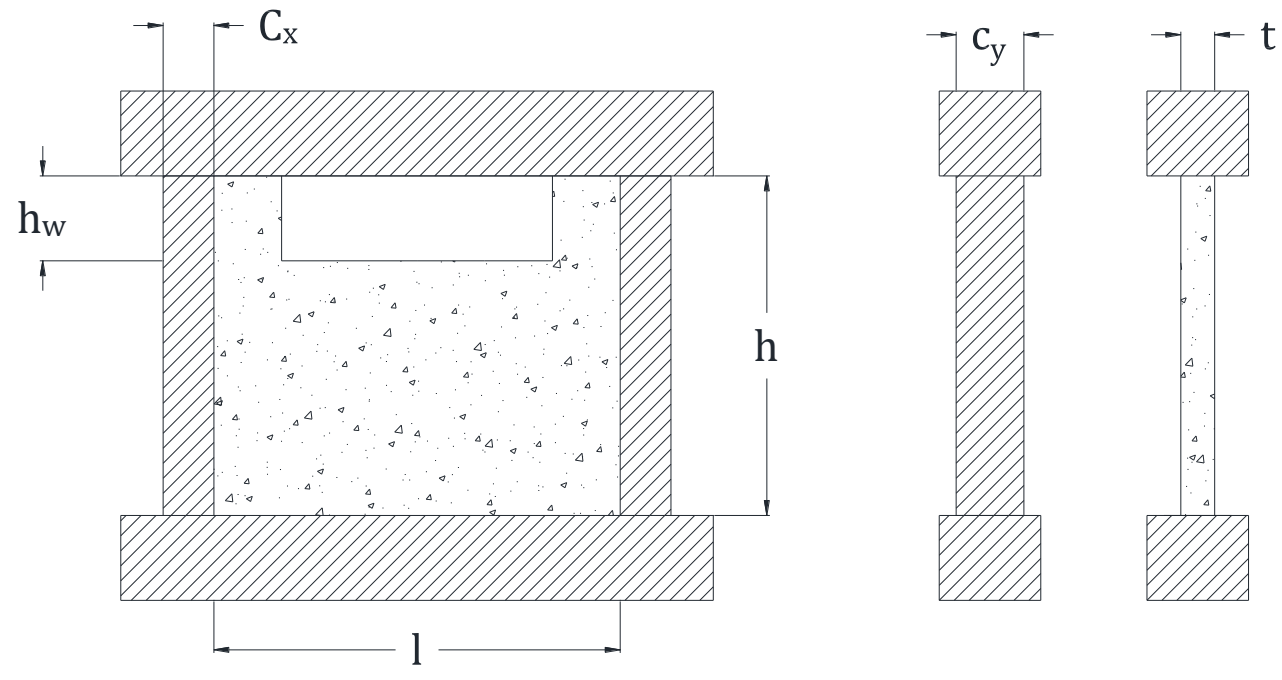

Şekil 2. Bant tipi boşluklu perde duvar modeli

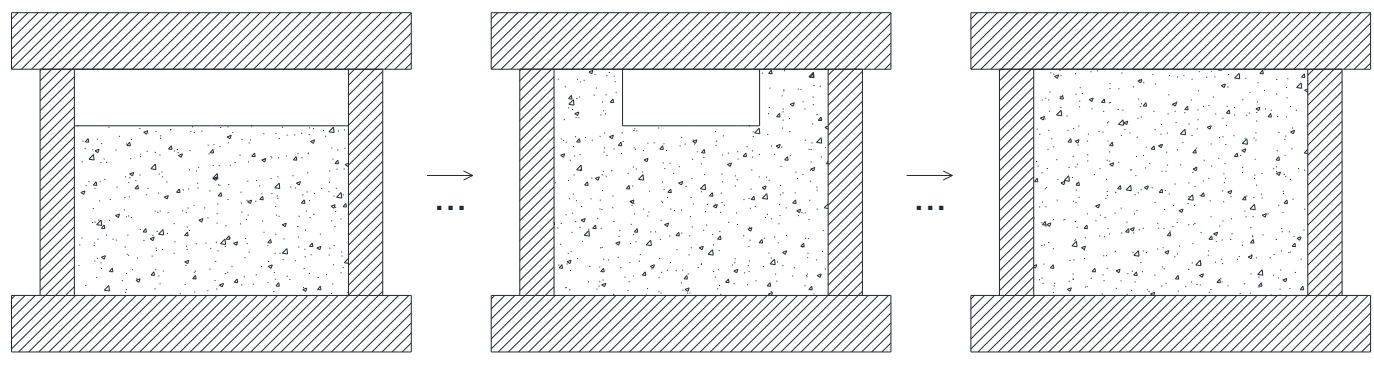

Şekil 3. Döngü içerisindeki çerçeve modelinin değişimi

Bu bağlamda Şekil 2'de görülen çerçeve modeli SAP2000'e OAPI aracılığıyla aktarılmak üzere C\# olarak kodlanmıştır. Yazılım başlangıçta bir veri kayıt dosyası oluşturmakta, sonrasında ise çerçeve modelini ve yüklemelerini SAP2000 yazılımında oluşturmaktadır. Bu aşamadan sonra ilgili parametrelerde analizi gerçekleştirerek belirlenen kesitlere ait verileri, veri kayıt dosyasına kaydederek sonraki adımın modelleme ve analizine geçmektedir. Şekil 3 'te görüldüğü üzere bu işlem pencere boşluğu tamamen ortadan kalkana kadar devam etmektedir. Modelde görünen ve kolonların yanına eklenerek her adımda boyutları $1 \mathrm{~cm}$ büyüyen duvarlar, kanat duvar, boşluklu çerçeve modelindeki boşluk tipi ise bant tipi boşluk olarak adlandırılmıştır. [5]

Analizi gerçekleştirilen çerçevelere ait özellikler Tablo 1'de verilmiştir. Çerçevelerin sol üst köşesinden Fx yanal 
yüklemesi yapılmış ve davranış değişimini daha sade biçimde gözlemleyebilmek amacıyla analizler lineer elastik olarak gerçekleştirilmiştir. Çerçevenin üstünde ve altında yer alan kirişler, rijit diyaframı temsil etmesi için çerçeveye kıyasla yüksek rijitlikte modellenmiştir.

Tablo 1. Farklı yüksekliklere bağlı olarak oluşturulmuş kombinasyonların listesi

\begin{tabular}{|c|c|c|c|c|c|}
\hline & Komb. 1 & Komb. 2 & Komb. 3 & Komb. 4 & Komb. 5 \\
\hline $\mathrm{h}(\mathrm{cm})$ & 250 & 275 & 300 & 325 & 350 \\
\hline $1(\mathrm{~cm})$ & 300 & 300 & 300 & 300 & 300 \\
\hline $\mathrm{t}(\mathrm{mm})$ & 150 & 150 & 150 & 150 & 150 \\
\hline $\mathrm{w}_{\mathrm{h}}\left(\mathrm{h}_{\mathrm{w}} / \mathrm{h}\right)$ & $\% 35$ & $\% 35$ & $\% 35$ & $\% 35$ & $\% 35$ \\
\hline $\mathrm{F}_{\mathrm{x}}(\mathrm{kN})$ & 100 & 100 & 100 & 100 & 100 \\
\hline $\mathrm{E}_{\mathrm{m}}(\mathrm{MPa})$ & 30000 & 30000 & 30000 & 30000 & 30000 \\
\hline $\mathrm{I}_{\mathrm{c}}\left(\mathrm{cm}{ }^{4}\right)$ & 67500 & 67500 & 67500 & 67500 & 67500 \\
\hline
\end{tabular}

Elde edilen grafikler, kanat duvar boyutunun büyümesiyle birlikte hem yer değiştirmelerde hem de kısa kolonlarda oluşan kesme kuvvetlerinde azalma olduğunu göstermiştir. Ancak bu değişim belli bir süre yüksek eğimle azalırken, dönüm noktasını barındıran belirsiz bir bölgeden sonra azalma eğimi düşmektedir. Fakat bu dönüm noktası her kombinasyonda farklılık göstermektedir. Ayrıca davranış eğrisinin doğrusal olmama durumu da her kombinasyon için kendine özel bir biçimde ortaya çıkmaktadır. Tüm bu sebepler doğrultusunda, elde edilen davranış eğrileri, Şekil 4 'te gösterilen değerlendirme yöntemi ile ele alınacaktır.

Verilen grafikte, davranış eğrisinin başlangıç ve bitiş noktası arasında bir doğru tanımlanmıştır. Daha sonra ilkiyle birlikte davranış eğrisinin tamamını kapsayacak ikinci bir doğru ilkine paralel olarak en uzak temas noktasına teğet geçecek şekilde konumlandırılmıştır. Bu iki doğru arasında kalan kısım "Davranış Koridoru" olarak adlandırılmış, bu koridorun genişliği ise "Davranış Koridoru Genişliği $(\Delta \mathrm{h})$ " olarak ifade edilmiştir. Davranış koridoru adıyla ifade edilen kavram, kombinasyonların davranış eğrilerini kıyaslamak için kullanılacak bir yöntem olup, herhangi bir optimum nokta bulunmasını sağlamamaktadır.

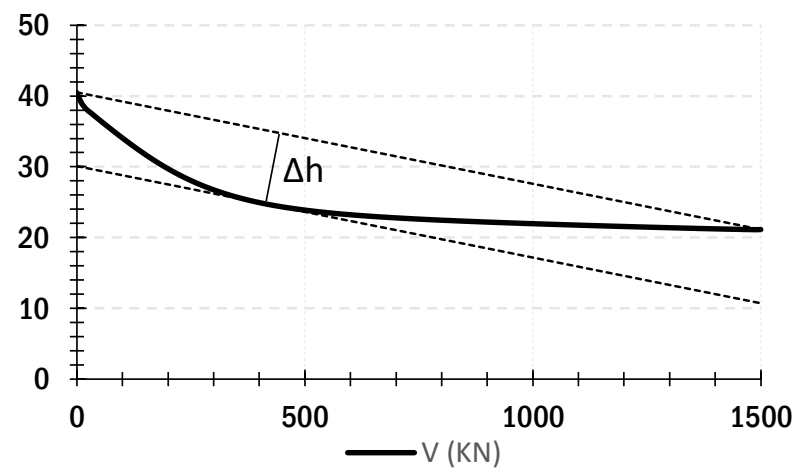

Şekil 4. Örnek davranış grafiği
Davranıș koridoru genişliğinin artması çerçeve davranışının doğrusallıktan uzaklaştığını göstermektedir. Davranış eğrisinin türevi incelendiğinde başlangıçta daha yüksek bir eğim söz konusuyken belli bir süre sonra davranışın eğimi giderek azalmaya başlamaktadır.

\section{BULGULAR}

Çalışma kapsamında incelenen çerçeve temiz yüksekliği için 5 farklı yükseklik $(250 \mathrm{~cm}, 275 \mathrm{~cm}, 300 \mathrm{~cm}, 325 \mathrm{~cm}$ ve 350 $\mathrm{cm})$ seçilmiştir. Çerçeve/Perde yüksekliği oranının sabit kalması sebebiyle, her bir kombinasyondaki serbest kolon boyu da aynı oranda artmaktadır.

Çerçeve/Perde oranının değerine bağlı olarak serbest kolon boyları Kombinasyon 1 için $87.5 \mathrm{~cm}$, Kombinasyon 2 için $96.25 \mathrm{~cm}$, Kombinasyon 3 için $105 \mathrm{~cm}$, Kombinasyon 4 için $113,75 \mathrm{~cm}$ ve son olarak Kombinasyon 5 için $122.5 \mathrm{~cm}$ 'dir.

Tablo 2'de verilen kesme grafiklerinden görüleceği üzere çerçeve yüksekliğinin artması davranış koridoru genişliğini belli bir miktarda artırmış olsa da, çerçeve/perde duvar yüksekliği oranı sabit kaldığı sürece kayda değer farklılık ortaya çıkmamaktadır. Ancak Şekil 5'te verilen ötelenme değerleri ve Şekil 6'da verilen ötelenme oranları göz önüne alındığında çerçevelerde ortaya çıkması muhtemel kısa kolon davranışı daha açık görünmektedir.

Şekil 6'da verilen ötelenme oranları Şekil 5'te verilen maksimum ötelenme değerlerinin, serbest kolon boyuna bölümünden elde edilmiştir. Görüldüğü üzere kesite gelen kesme kuvveti yaklaşı olarak aynı kalırken serbest kolon boyunun azalması kolonların ötelenme kapasitesini doğrusal olmayan biçimde azaltmakta ve buna bağlı olarak kısa kolon davranışının görülme olasılığı da artmaktadır. Elde edilen ötelenme oranları ve davranış koridoru genişliği değerleri, çerçevelere ait a/d oranlarıyla paralellik göstermektedir. İlgili değerler Tablo 3 'te verilmiştir. 
Tablo 2. Kanat duvar boyu değişimine bağlı olarak ortaya çıkan kesme kuvveti ve moment değeri değişim grafikleri

\begin{tabular}{|c|c|c|}
\hline & $\begin{array}{l}\text { Sol kolonun serbest boyundaki kesme } \\
\text { kuvvetinin kanat duvar boyuna bağlı } \\
\text { değişimi }\end{array}$ & $\begin{array}{l}\text { Sol kolonun serbest boyundaki maksimum ve } \\
\text { minimum moment değerinin kanat duvar } \\
\text { boyuna bağlı değişimi }\end{array}$ \\
\hline 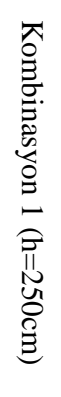 & 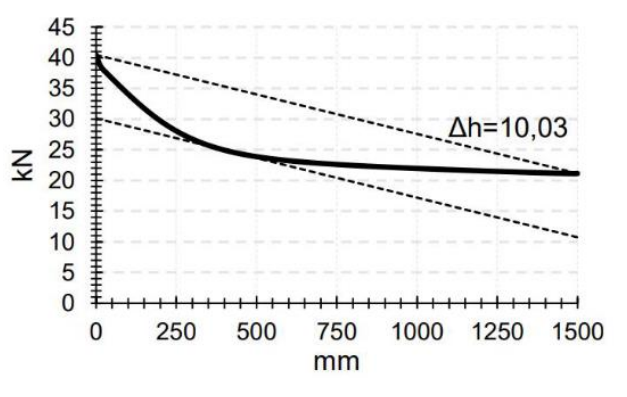 & 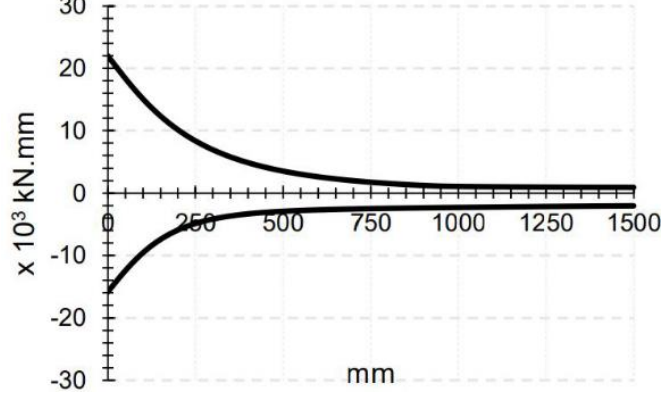 \\
\hline 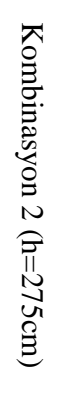 & 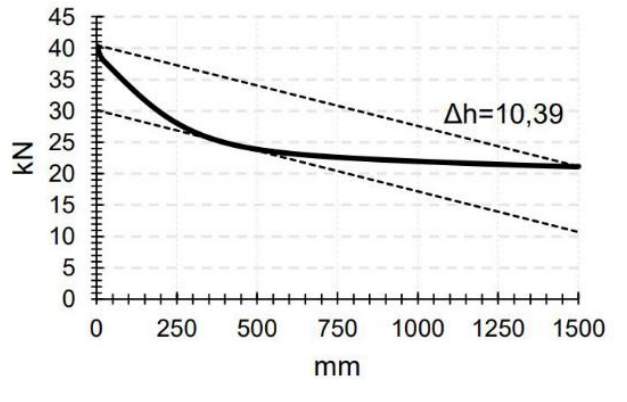 & -30主 \\
\hline 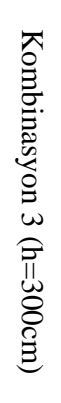 & 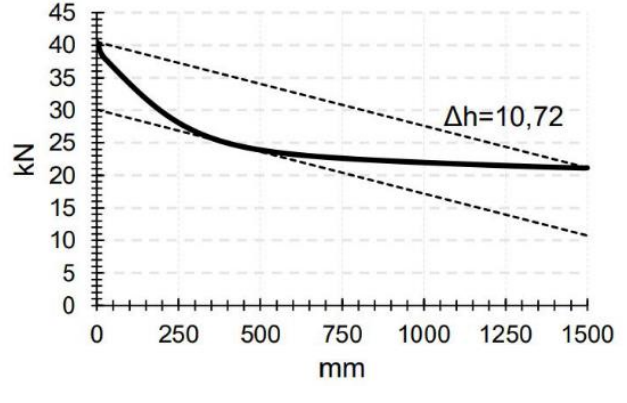 & $\begin{array}{lllll}, 1,+1+1 & \\
500 & 750 & 1000 & 1250 & 1500\end{array}$ \\
\hline 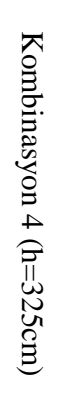 & 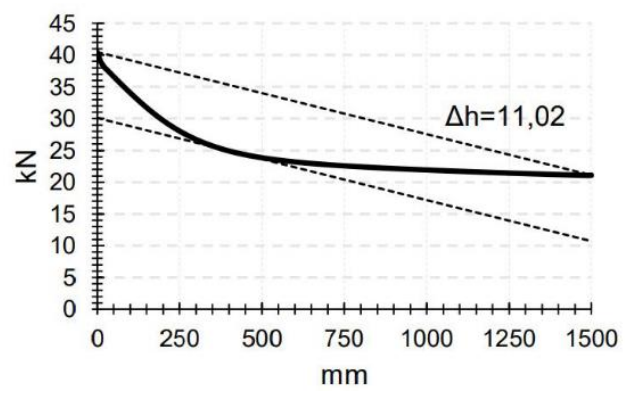 & mm \\
\hline 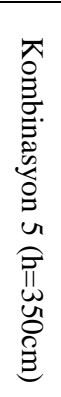 & 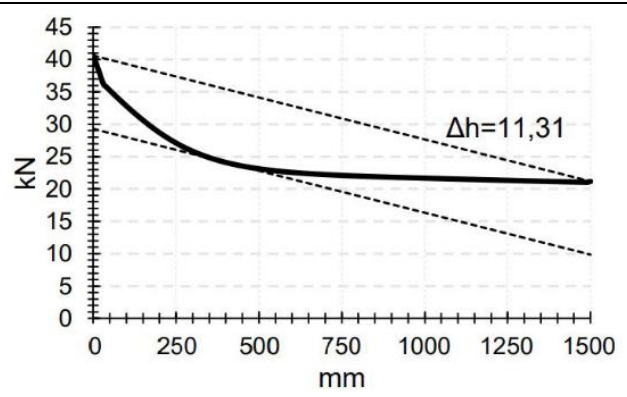 & -30 \\
\hline
\end{tabular}




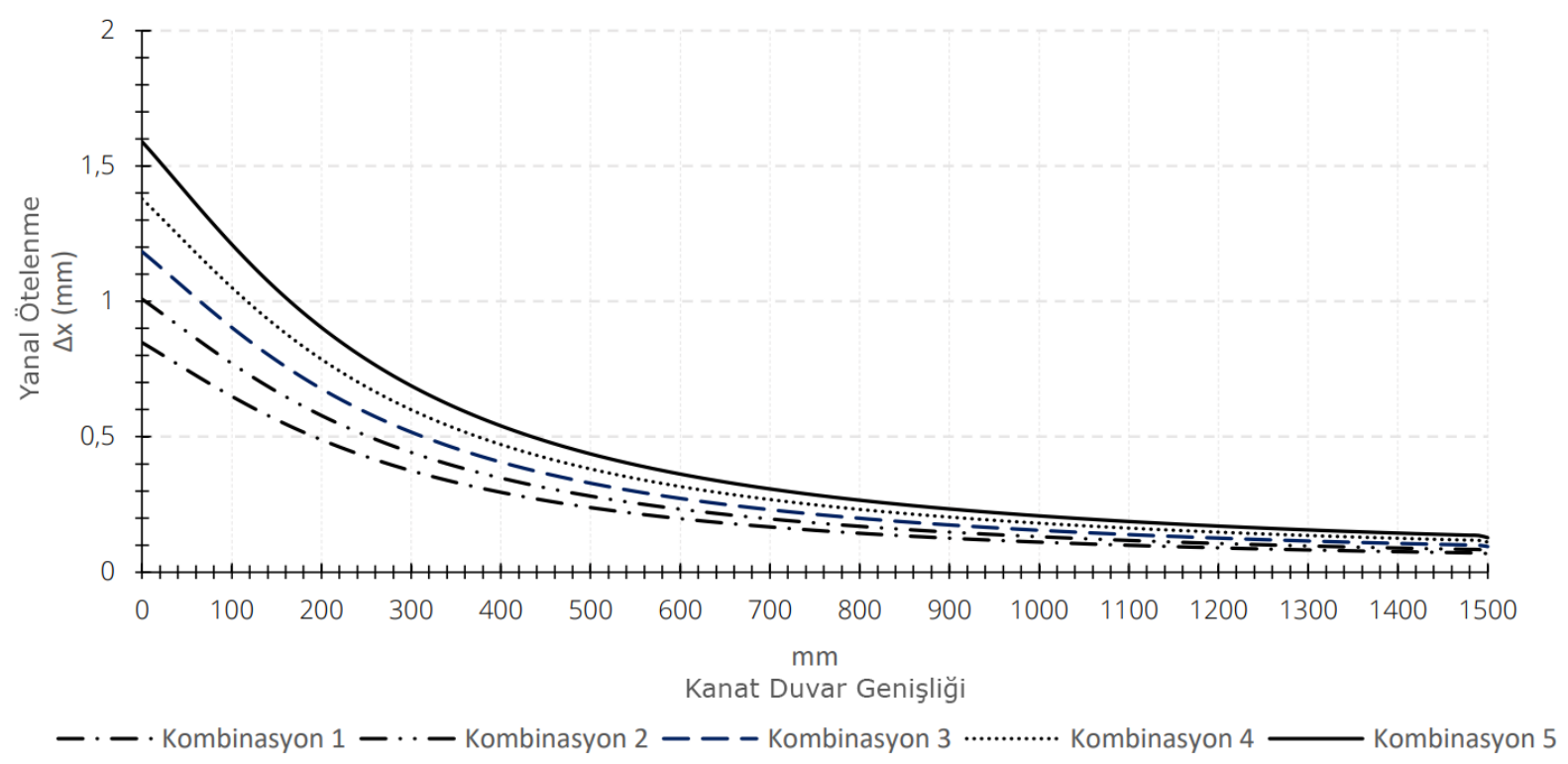

Şekil 5. Kanat duvar boyu değişimine bağlı olarak yanal ötelenmelerin değişsimi

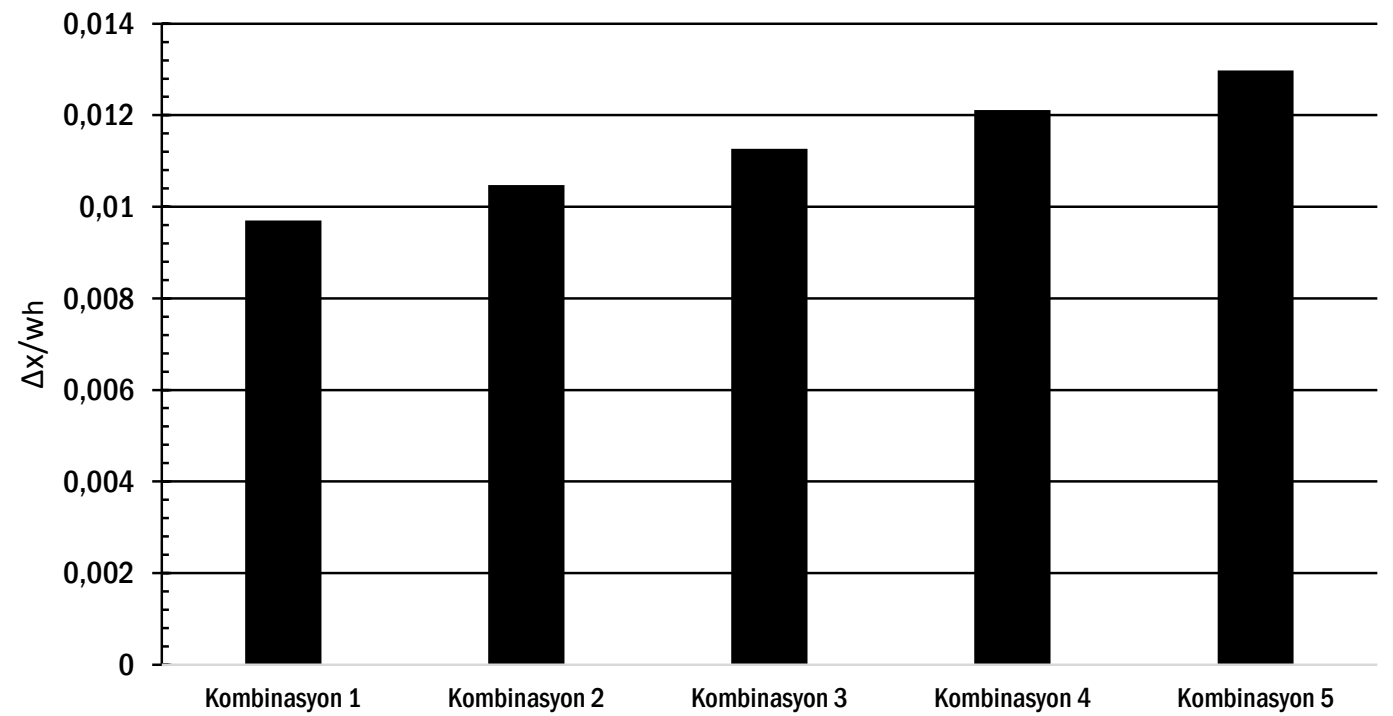

Şekil 6. En büyük ötelenme oranları

Tablo 3. Çerçevelere ait a/d, $\Delta \mathrm{h}, \Delta \mathrm{x} /$ wh değerleri

\begin{tabular}{|l|l|l|l|}
\hline & \multicolumn{1}{|c|}{$\mathrm{a} / \mathrm{d}$} & & \multicolumn{1}{|c|}{$\Delta \mathrm{h} / \mathrm{wh}$} \\
\hline Kombinasyon 1 & 3,2 & 10,0 & 0,0097 \\
\hline Kombinasyon 2 & 3,6 & 10,4 & 0,0105 \\
\hline Kombinasyon 3 & 3,9 & 10,7 & 0,0113 \\
\hline Kombinasyon 4 & 4,2 & 11,0 & 0,0121 \\
\hline Kombinasyon 5 & 4,5 & 11,3 & 0,0129 \\
\hline
\end{tabular}




\section{DEĞERLENDİRME VE SONUÇ}

Yapılan analizler, boşluklu perde duvarlarda çerçeve yüksekliğinin değişmesinin kolonlarda ortaya çıkan kesme kuvveti değerlerini önemli ölçüde değiştirmediğini göstermiştir. Analizi yapılan çerçevelerin tümünün tam dolu çerçeve ve bant pencereli çerçeveli hallerinde ortaya çıkan kesme kuvveti değerlerinin yaklaşık eşit olduğu görülmüştür. Ancak bu maksimum ve minimum noktalar arasındaki davranış eğrilerinin doğrusallığ farklılaşmaktadır. Bu doğrusallıktan uzaklaşma değişimini gözlemlemek adına kullanılan davranış koridoru genişliği açısından, en uzun ve en kisa serbest kolon boyuna sahip çerçeveler arasında yüzde 13'lük bir fark ortaya çıkmıştır. 1 . ve 2. kombinasyonlar arasında serbest kolon boyu yüzde 10 artış gösterirken, yanal ötelenme artışı yüzde 18 olmuştur. Ötelenme oranları arasındaki farlılığın da temelini oluşturan bu durum takip eden kombinasyonlar arasında da kendini göstermiştir. Görüldüğü üzere her bir kombinasyondaki kesme kuvveti değerlerinin birbirine son derece yakın olmasına rağmen sünek davranışın engellenmesi, ötelenme oranlarını azaltmakta haliyle olası kısa kolon oluşumu ihtimalini de artırmaktadır.

\section{KAYNAKÇA}

[1] T.C. Bayındırlık ve İskan Bakanlığı Afet İşleri Genel Müdürlüğü Deprem Araştırma Dairesi, Deprem bölgelerinde yapilacak binalar hakkinda yönetmelik. Turkey, 2007.

[2] B. Yön and H. Şahin, "ÇOK KATLI BETONARME BINALARDA ZEMIN SINIFINA GÖRE DEPREM PERDESİ ORANININ TESPITİ," Uludağ Üniversitesi Mühendislik-Mimarlık Fakültesi Derg., pp. 57-73, 2009.

[3] E. Atımtay, Çerçeveli ve Perdeli Betonarme Sistemlerin Tasarımı. Ankara: Bizim Büro Basımevi Yayın Dağıtım San. Tic. Ltd. Şti., 2000.

[4] İ. H. Çağatay, "Binalarda Kısa Kolona Etki Eden Parametrelerin Incelenmesi," in 6. Ulusal Deprem Muhendisliği Konferansı, 2007.

[5] M. Hüsem, S. Altin, S. Pul, M. Bikçe, and E. Emsen, "Betonarme Perdelerde Bırakılan Bant Tipi Boşluklar Nedeniyle Depremde Oluşan Kısa Kolon Etkisinin İyileştirilmesi," 2013.

[6] B. S. Smith, "Methods for predicting the lateral stiffness and strength of multi-storey infilled frames," Build. Sci., vol. 2, no. 3, pp. 247-257, 1967.

[7] A. W. Hendry, Structural Masonry. London: MACMILLAN Education, 1990.

[8] P. G. Asteris, "Lateral Stiffness of Brick Masonry Infilled Plane Frames," J. Struct. Eng., vol. 129, no. 8, pp. 1071-1079, 2003.

[9] H. S. Kim and D. G. Lee, "Analysis of shear wall with openings using super elements,” Eng. Struct., vol. 25, no. 8, pp. 981-991, 2003.

[10] H. Guan, C. Cooper, and D.-J. Lee, "Ultimate strength analysis of normal and high strength concrete wall panels with varying opening configurations," Eng. Struct., vol. 32, no. 5, pp. 1341-1355, 2010.
[11] P. G. Asteris, D. M. Cotsovos, C. Z. Chrysostomou, A. Mohebkhah, and G. K. Al-Chaar, "Mathematical micromodeling of infilled frames: State of the art," Eng. Struct., vol. 56, 2013.

[12] R. Chittiprolu and R. P. Kumar, "Significance of Shear Wall in Highrise Irregular Buildings," Int. J. Educ. Appl. Res., vol. 4, no. 2, pp. 35-37, 2014.

[13] X. Lu, L. Xie, H. Guan, Y. Huang, and X. Lu, “A shear wall element for nonlinear seismic analysis of supertall buildings using OpenSees," Finite Elem. Anal. Des., vol. 98, pp. 14-25, Jun. 2015.

[14] M. Bolhassani, A. A. Hamid, C. Johnson, and A. E. Schultz, "Shear strength expression for partially grouted masonry walls," Eng. Struct., vol. 127, pp. 475-494, 2016.

[15] M. Yekrangnia and M. Mohammadi, "A new strut model for solid masonry infills in steel frames," Eng. Struct., vol. 135, pp. 222-235, 2017.

[16] A. Mohyeddin, S. Dorji, E. F. Gad, and H. M. Goldsworthy, "Inherent limitations and alternative to conventional equivalent strut models for masonry infillframes," Eng. Struct., vol. 141, pp. 666-675, 2017.

[17] T. C. Liauw, "An approximate method of analysis for infilled frames with or without opening," Build. Sci., vol. 7, no. 4, pp. 233-238, 1972.

[18] C. L. Lin, C Y. Kuo, "Behavior of shear wall with Opening," in Ninth World Conference on Earthquake Engineering, 1988, pp. 535-540.

[19] P. G. Asteris, "Finite element micro-modeling of infilled frames," Electron. J. Struct. Eng., vol. 8, no. 8, pp. $1-11,2008$.

[20] S. Altin, Ö. Anil, M. E. Kara, and M. Kaya, "An experimental study on strengthening of masonry infilled RC frames using diagonal CFRP strips," Compos. Part B Eng., vol. 39, no. 4, pp. 680-693, 2008.

[21] M. Marius, "Seismic behaviour of reinforced concrete shear walls with regular and staggered openings after the strong earthquakes between 2009 and 2011," Eng. Fail. Anal., vol. 34, pp. 537-565, 2013.

[22] M. Marius, "Failure analysis of RC shear walls with staggered openings under seismic loads," Eng. Fail. Anal., vol. 41, pp. 48-64, 2014.

[23] R. Sharma and J. A. Amin, "Effects of opening in shear walls of 30- storey building," vol. 2, pp. 44-55, 2015.

[24] X. Chen and Y. Liu, "Finite Element Study of the Effect of Interfacial Gaps on the in-Plane Behaviour of Masonry Infills Bounded by Steel Frames," Structures, vol. 10, pp. 1-12, 2016.

[25] E. Nasiri and Y. Liu, "Development of a detailed 3D FE model for analysis of the in-plane behaviour of masonry infilled concrete frames," Eng. Struct., vol. 143, pp. 603-616, 2017.

[26] K. A. Woodward and J. O. Jirsa, "Influence of Reinforcement on RC Short Column Lateral Resistance," J. Struct. Eng., vol. 110, no. 1, pp. 90-104, 1984.

[27] G. A. Hartley, "Radial Contour Methods of Biaxial Short Column Design," J. Am. Concr. Inst., vol. 82, no. 5, pp. 693-700, 1985.

[28] Y. Harumi, T. Yasuo, N. Masayuki, and R. Younggon, "Study on shear failure mechanisms of 
reinforced concrete short columns," Eng. Fract. Mech., vol. 35, no. 1-3, pp. 277-289, 1990.

[29] G. Işık, "BETONARME BINALARIN ZEMIN KATINDA OLUŞABILLEN KISA KOLON VE YUMUŞAK KAT DAVRANIŞININ INCELENMESI,," Karadeniz Teknik Üniversitesi, 2006.

[30] M. Bikçe, M. C. Geneş, and S. K. A. Zubaroğlu, "Betonarme bir yapıda duvarsız ve duvarlı hallerin dinamik testleri," in 1. Türkiye Deprem Mühendisliği ve Sismoloji Konferans1, 2011, pp. 1-8.
[31] M. Artar and A. T. Daloğlu, "Optimum weight design of steel space frames with semi-rigid connections using harmony search and genetic algorithms," Neural Comput. Appl., Oct. 2016.

[32] A. T. Daloglu, M. Artar, K. Özgan, and A. I. Karakas, "Optimum design of steel space frames including soil-structure interaction," Struct. Multidiscip. Optim., vol. 54, no. 1, pp. 117-131, 2016.

[33] Computers \& Structures, “CSi API Documentation.” 2015. 